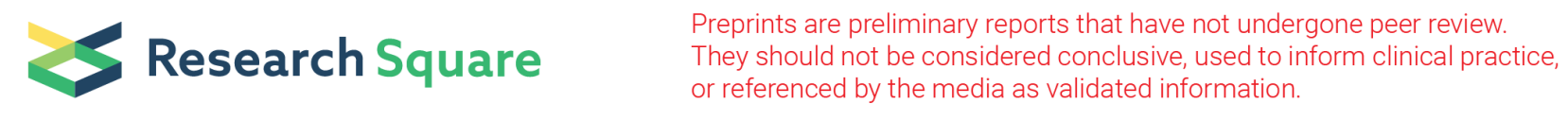

\title{
Sensitivity and specificity of the URAM scale for Dupuytren contracture: A systematic review and meta-analysis
}

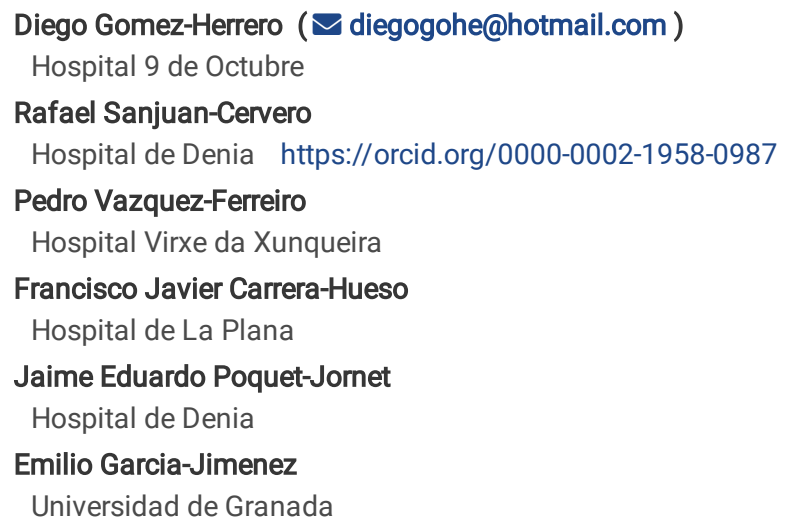

\section{Research}

Keywords: "Dupuytren Contracture", “Meta-Analysis", "ROC Curve", “URAM”

Posted Date: June 2nd, 2020

DOl: https://doi.org/10.21203/rs.3.rs-30621/v1

License: () (1) This work is licensed under a Creative Commons Attribution 4.0 International License. Read Full License 


\section{Abstract \\ Background}

The URAM (Unité Rhumatologique des Affections de la Main) scale is a patient-reported functional outcome measurement tool validated for exclusive use in Dupuytren contracture (DC) a condition in which one or more fingers become permanently bent in a flexed position. The current study's purposes were to evaluate: How sensitive and specific is the URAM scale for defining quality of life in patients with in DC and how sensitive to change is the URAM scale after treatment.

\section{Methods}

We performed a meta-analysis of all relevant articles published in PubMed, Embase, Cochrane, Google Scholar, LILACS and in various gray literature databases that describe the use of the URAM. We built three models: a hierarchical summary receiver operating characteristic (HSROC) model to determine the optimal threshold for defining DC, a difference in means models to assess the magnitude of the effect of different treatment modalities, and a meta-regression model to determine the effect on patient quality of life questionnaires according to variations in Tubiana scores after treatment (URAM).

\section{Results}

The HSROC and bivariate models showed a sensitivity of $80.23 \%$ (95\% Cl: 75.66 to 84.14$)$ and an overall specificity of $2.61 \%$ (95\%Cl: $1.11-6.05)$. The second model showed an overall difference in means of $1.95(95 \% \mathrm{Cl}:-2.86$ to -1.04$)$. The coefficient obtained in the meta-regression model was -1.666 (95\%Cl: -4.183 to 0.851$)$.

\section{Conclusion}

The URAM scale is highly sensitive to changes in DC but has low specificity. It also showed a strong correlation with worsening of finger contracture.

\section{Introduction}

Dupuytren contracture (DC) is a fibroproliferative disease of the palmar fascia that can affect one or both hands. It causes progressive digital contracture that prevents patients from straightening their fingers, affecting hand function, performance of basic activities of daily living, and quality of life (Eaton et al. 2014).

Treatments include surgical procedures, such as fasciotomy, partial fasciectomy (FSC), and dermofasciectomy, and minimally invasive procedures, such as collagenase Clostridium histolyticum (CCH) injections and needle aponeurotomy (NA) (Eaton 2017). None of these treatments are curative and therefore many patients develop recurrent disease and require repeat treatment (Warwick 2017). Much research has been done on treatment outcomes in DC, with studies evaluating functional outcomes, patient satisfaction, and perceived quality of life using physical measures and self-report questionnaires (Engstrand et al. 2014). Patient satisfaction with treatment or with treatment outcomes is a multidimensional concept that can be difficult to define and measure and it also depends on aspects related to healthcare structure and delivery (Engstrand et al. 2016). In addition, the studies published to date have used different methods and asked different questions. Some authors have recommended using the URAM (Unité Rhumatologique des Affections de la Main) scale to monitor disease progression and treatment success and enable comparisons between different treatment modalities in DC (Ball et al. 2013).

The URAM scale was specifically designed to evaluate hand function in DC by the Rheumatology Department at Hospital Lariboisere in Paris, France in 2011. It is the first patient-reported functional outcome measurement tool validated for exclusive use in DC and has been shown to have adequate psychometric properties (Beaudreuil et al. 2011). It consists of nine multiple-choice questions, meaning it is sufficiently short and easy to use in both daily practice and clinical trials (Stromberg et al. 2016, Verstreken et al. 2016). It assesses patients' perceived ability to perform a range of activities, including activities of daily living, and also addresses symptoms such as stiffness and loss of strength (Bernabé et al. 2014). Several studies have evaluated the reliability (good to excellent) and responsiveness of the scale (Binhammer 2018), which in addition has been adapted and validated for use in different languages (Beaudreuil et al. 2011).

The aim of this study was to perform a systematic review and meta-analysis of the sensitivity and specificity of the URAM scale in terms of its ability to define quality of life in patients with DC and its responsiveness to changes in disease severity following treatment.

\section{Methods}

The systematic review was performed according to the recommendations of Eden et al. (Eden et al. 2011) on review methods, data sources, and search strategies. We addressed two review questions:

1. Using the Tubiana scale as a reference test, how sensitive and specific is the URAM scale for defining quality of life in patients with in DC? 
2. How sensitive to change is the URAM scale after treatment with FSC and $\mathrm{CCH}$ ?

We performed a systematic search of PubMed, EMBASE, Cochrane, Google Scholar, LILACs, and Web of Science for articles published between January 1, 1990 and June 1, 2019.

The search criteria used in all the databases were combinations of the terms "Unité Rhumatologique des Affections de la Main", "URAM", "Dupuytren Contracture", and "Dupuytren".

Two reviewers (PVF and DGH) independently searched the databases and reviewed the articles retrieved. They also hand searched the reference lists of relevant articles and reviewed the gray literature to identify clinical trial reports and conference proceedings.

Clinical trials, cohort studies, and case-control studies that had used the URAM scale to evaluate DC were included. Authors were contacted when specific information on the use of this scale was missing. To minimize publication bias, no language constraints were placed.

\section{Study Selection}

Two researchers (PVF and DGH) independently screened the titles and abstracts to identify suitable texts, which they then reviewed in depth. When the researchers disagreed on whether a particular article should be included or excluded, the article was reviewed by a third researcher (FJCH) to break the tie.

\section{Data Extraction and Risk of Bias Assessment}

Working separately, PVF and DGH transferred all relevant data from the selected articles into standardized forms. The reliability of the entries was checked by another researcher (JEPJ). In addition to effect variables (mean [SD] pre- and post-intervention URAM and Tubiana scores), the data recorded included demographic variables (age, gender, and hand and radius affected) and variables for the stratification analyses in the meta-analysis (e.g., quality, language, study type).

As the studies included in the meta-analysis differed in type, their quality was assessed using the STROBE (STrengthening the Reporting of OBservational studies in Epidemiology) checklist (von Elm et al. 2014) applied separately by two researchers for each article. To minimize bias, a score of 15 or higher was used to identify high-quality studies. Discrepancies (i.e., differences in scores that placed a given study above or below the cutoff of 15 ) were resolved by a third researcher (RSC).

\section{Statistics}

Three meta-analysis models were used to answer the research questions: a hierarchical summary receiver operating characteristic (HSROC) model, a difference in means model for pre- and post-treatment URAM scores, and a meta-regression model adjusted for time since treatment.

For the HSROC model, tables summarizing Tubiana and URAM scores reported in each of the studies were created. In both cases, it was assumed that the scores were normally distributed. The data were then presented in $2 \times 2$ contingency tables with the URAM scale as the index test and the Tubiana scale as the reference test. The respective thresholds used were 2.5 and 1 . Prevalence of DC was established at $100 \%$. In other words, it was assumed that there were no true negatives, that it is that all the negative results for the reference test were false negatives. Enabling continuity correction, we then built a hierarchical multinomial regression HSROC model (Rutter et al. 2001), which converts the distribution of the two variables, allowing calculation of the overall ROC curve under the assumption that there is an underlying curve for each of the studies included. Each curve is determined by two parameters, $a$ and $\beta$, which denote accuracy and asymmetry, respectively. Using these parameters and a $\theta$ parameter to denote the positivity threshold, distribution tables were generated for each study assuming that while the distribution of parameters would vary between studies, it would be normal and random (random-effects model). We then estimated the overall ROC curve together with the optimal threshold and corresponding confidence interval. The bivariate model was applied to directly model specificity and sensitivity based on the assumption that the Napierian logarithm of the odds ratio had a normal bivariate distribution in the different studies analyzed (Reitsma et al. 2005).

For the second model, standardized mean differences in pre- and post-treatment URAM scores were computed using Cohen's D and appropriate weighting. The most conservative model was selected in each case (Higgins et al. 2011). Differences of over $10 \%$ were considered to be clinically significant and the results were stratified by type of intervention (FSC or $\mathrm{CCH}$ ). Each group was finally assigned an overall value.

For the meta-regression model, the dependent variable was change in URAM scores after treatment (differences in means before and after FSC or CCH) and the independent variables were Tubiana scores, time since treatment, type of treatment, age, and sex. The model with the greatest explanatory power was selected.

Heterogeneity between studies was investigated using the $\mathrm{I}^{2}$ statistic, with high heterogeneity defined as a value of over 50\% (Higgins et al. 2002). Potential sources of heterogeneity were investigated by subgroup analyses (study setting, language, ethnic origin), and the effect of outliers was analyzed in a sensitivity analysis in which studies were excluded one by one.

Analyses were conducted using the metan, metacum, metafunnel, and metandi features in Stata version 15. Differences in means were considered to be significant when the confidence intervals did not cross 0 and clinically significant when there was a difference of at least $10 \%$. Publication bias was assessed using funnel plots and the Begg-Mazumdar test (Begg et al. 1994). 


\section{Funding and potential conflicts of interest}

The whole investigation has been financed by own funds. Each author certifies that he has no commercial associations that might pose a conflict of interest in connection with the submitted article. All authors have completed and submitted the Conflict of Interest Disclosure Form and none were reported.

\section{Results}

Our search strategy retrieved 384 articles (Fig. 1) but 50 of these were excluded due to duplication. After screening the titles and abstracts of the remaining 334 articles, 313 were excluded (inadequate study design, missing data, different definitions of disease or disease severity, and publication in a language that could not be translated). Of the 21 articles selected for full-text review, 11 were excluded as they did not contain the information needed for our calculations (URAM scores, Tubiana scores, or degrees of contracture). Ten articles thus were included in the meta-analysis. Eight were used in the HSROC model, nine in the difference in means model, and 10 in the meta-regression model. The main characteristics of the studies are shown in Table 1.

Table 1

Characteristics of the studies included in the meta-analysis.

\begin{tabular}{|c|c|c|c|c|c|c|c|c|c|c|c|c|c|c|c|}
\hline Study & Year & $\mathbf{N}$ & Country & Type & Language & Age & Male & NA & $\mathrm{CCH}$ & Hand & R5 & R4 & R3 & R2 & R1 \\
\hline $\begin{array}{l}\text { Beaudreuil } \\
\text { et al. }\end{array}$ & 2011 & 53 & France & $\mathrm{CH}$ & English & 63.2 & 83.02 & 0 & 100 & 54.72 & N.A & N.A & N.A & N.A & N.A \\
\hline $\begin{array}{l}\text { Scherman } \\
\text { et al. }\end{array}$ & 2013 & 93 & Sweden & $\mathrm{CH}$ & English & 67 & 86.75 & 50 & 50 & 53.49 & 55.81 & 37.21 & 6.98 & 0 & 0 \\
\hline $\begin{array}{l}\text { Warwick } \\
\text { et al. }\end{array}$ & 2013 & 254 & International & $\mathrm{CH}$ & English & 60 & 87.79 & 0 & 100 & 75.59 & 75.20 & 68.90 & 29.53 & 09.06 & 2.36 \\
\hline $\begin{array}{l}\text { Bernabé et } \\
\text { al. }\end{array}$ & 2014 & 83 & France & $\mathrm{CH}$ & English & 63 & 83.02 & 0 & 0 & N.A & N.A & N.A & N.A & N.A & N.A \\
\hline $\begin{array}{l}\text { Stromberg } \\
\text { et al. }\end{array}$ & 2016 & 140 & Sweden & CT & English & 67.5 & 85.26 & 51 & 49 & 58.57 & 51.43 & 35.00 & 06.43 & 0 & 0 \\
\hline $\begin{array}{l}\text { Broekstra } \\
\text { et al. }\end{array}$ & 2017 & 233 & Holland & $\mathrm{CH}$ & English & 65.5 & 65.35 & 0 & 0 & N.A & N.A & N.A & N.A & N.A & N.A \\
\hline $\begin{array}{l}\text { Harrison } \\
\text { et al. }\end{array}$ & 2017 & 71 & UK & $\mathrm{CH}$ & English & 65.7 & 76.06 & 54 & 46 & 80.28 & 57.75 & 12.68 & 29.58 & 0 & 0 \\
\hline $\begin{array}{l}\text { Stromberg } \\
\text { et al. }\end{array}$ & 2018 & 152 & Sweden & CT & English & 66.5 & 85.27 & 50 & 50 & 58.34 & 51.28 & 41.67 & 07.05 & N.A & N.A. \\
\hline $\begin{array}{l}\text { Beaudreuil } \\
\text { et al. }\end{array}$ & 2018 & 30 & France & $\mathrm{CH}$ & English & 72 & 83.34 & 100 & 0 & N.A & N.A & N.A & N.A & N.A & N.A \\
\hline $\begin{array}{l}\text { Wiseman } \\
\text { et al. }\end{array}$ & 2018 & 136 & Australia & $\mathrm{CH}$ & English & 66 & 80.15 & 0 & 100 & 75.18 & N.A & N.A & N.A & N.A & N.A \\
\hline
\end{tabular}

Application of the HSROC (Rutter et al. 2001) and bivariate models showed an overall sensitivity of $80.23 \%$ (95\% Cl: 75.66 to 84.14 ) and specificity of $2.61 \%$, (95\% Cl: 1.11 to 6.05$)$. The diagnostic odds ratio was $0.109,(95 \% \mathrm{Cl}: 0.041$ to 0.292$)$, with a positive predictive value of 0.824 and a negative predictive value of 7.546 (Table 2). The reference value together with its $95 \%$ prediction region is shown in Fig. 2. 
Table 2

Parameters computed for the HSROC and bivariate models.

\begin{tabular}{|c|c|c|c|c|c|c|c|}
\hline Model & Parameter & Coef. & Std. Err. & $\mathbf{z}$ & $P>Z$ & \multicolumn{2}{|c|}{ [95\% Conf. Interval] } \\
\hline \multirow[t]{5}{*}{ Bivariate } & E(logitSe) & 1.401 & 0.136 & & & 1.134 & 1.669 \\
\hline & E(logitSp) & -3.616 & 0.446 & & & -4.490 & -2.742 \\
\hline & Var(logitSe) & 0.036 & 0.051 & & & 0.002 & 0.577 \\
\hline & Var(logitSp) & 0.350 & 0.652 & & & 0.009 & 13.436 \\
\hline & Corr(logits) & 1.000 & - & & & - & - \\
\hline \multirow[t]{5}{*}{ HSROC } & Lambda & 0.428 & 2.376 & & & -4.228 & 5.085 \\
\hline & Theta & 2.261 & 0.160 & & & 1.948 & 2.574 \\
\hline & beta & 1.138 & 1.034 & 1.100 & 0.271 & -0.888 & 3.164 \\
\hline & s2alpha & 0.449 & 0.580 & & & 0.036 & 5.631 \\
\hline & s2theta & 0.000 & - & & & - & - \\
\hline \multirow[t]{6}{*}{ Summary pt. } & $\mathrm{Se}$ & 0.802 & 0.022 & & & 0.757 & 0.841 \\
\hline & Sp & 0.026 & 0.011 & & & 0.011 & 0.061 \\
\hline & DOR & 0.109 & 0.055 & & & 0.041 & 0.292 \\
\hline & LR+ & 0.824 & 0.027 & & & 0.773 & 0.878 \\
\hline & LR- & 7.546 & 3.601 & & & 2.961 & 19.228 \\
\hline & 1/LR- & 0.133 & 0.063 & & & 0.052 & 0.338 \\
\hline \multicolumn{8}{|c|}{ Covariance between estimates of E(logitSe) \& E(logitSp) 0,0174904; Log likelihood - 32,050571 } \\
\hline \multicolumn{8}{|c|}{$\begin{array}{l}\text { E(logitSe): logit-transformed sensitivity; E(logitSP): logit-transformed specificity; var(logitSe): variance of logit-transformed sensitivity; var(logitSp): } \\
\text { variance of logit-transformed specificity; Corr(logits): correlation; Lambda: mean accuracy parameter; theta: positivity parameter; beta: asymmetry } \\
\text { parameter; s2alpha: variance of alpha parameter, s2theta: variance of theta parameter; Se: sensitivity; Sp: specificity; DOR: Diagnostic odds ratio; LR } \\
+ \text { and -: positive and negative likelihood ratios; } 1 \text { /LR-: inverse of the negative likelihood ratio. }\end{array}$} \\
\hline
\end{tabular}

In the differences in mean model, we obtained a value of -1.30 ( $95 \% \mathrm{Cl}:-1.77$ to -0.83$)$ for FSC and -2.75 (95\% $\mathrm{Cl}:-4.73$ to -0.78$)$ for $\mathrm{CCH}$. The overall value was -1.95 (95\% Cl: -2.86 to -1.04$)$ (Fig. 3).

The only significant variable in the meta-regression analysis of the influence of variations in Tubiana scores on URAM scores was time between treatment and completion of the URAM questionnaire (Table 3). The coefficient for this model was 1.666 (95\% Cl: -4.183 to 0.851$)$.

Table 3

Meta-regression

\begin{tabular}{|c|c|c|c|c|c|c|}
\hline \multicolumn{4}{|c|}{ Random-effects model estimate of between-study variance } & \multicolumn{3}{|c|}{$\mathrm{Tau}^{2}=3.18$} \\
\hline \multicolumn{4}{|c|}{$\%$ residual variation due to heterogeneity } & \multicolumn{3}{|c|}{$P^{2}=75.40 \%$} \\
\hline \multicolumn{4}{|c|}{ Proportion of between-study variance explained } & \multicolumn{3}{|c|}{$R^{2}=28.85 \%$} \\
\hline & Coef. & Std. Err. & $\mathrm{t}$ & $P>|t|$ & \multicolumn{2}{|c|}{$95 \%$ Conf. Interval } \\
\hline Tubiana & -1.666 & 0.979 & -1.70 & 0.150 & -4.183 & 0.851 \\
\hline Time & 0.014 & 0.009 & 1.55 & 0.182 & -0.009 & 0.037 \\
\hline Constant & -13.392 & 2.713 & -4.94 & 0.004 & -20.366 & -6.417 \\
\hline
\end{tabular}

\section{Discussion}

Our meta-analysis showed high sensitivity $(80.2 \%, 95 \% \mathrm{Cl}: 75.7-84.1 \%)$ and low specificity $(2.6 \%, 95 \%$ Cl: $1.11-6.1 \%)$ at the optimal threshold for the URAM scale as a diagnostic test for DC. The scale was also very sensitive to change after treatment with $\mathrm{FSC}$ and $\mathrm{CCH}$, with an overall difference in means of -1.95 ( $95 \% \mathrm{Cl}$ : -2.86 to -1.04$)$. It was more responsive to changes after $\mathrm{CCH}$. The scale was also able to capture the effect of time since treatment, although to a lesser extent (nonsignificant coefficient). The high sensitivity observed is to be expected as the URAM scale contains several questions on hand mobility. It is also consistent with the strong correlation observed between URAM and Tubiana scores in previous validations (Beaudreuil et al. 2011) and with high sensitivity values reported for the DASH (Disabilities of the Arm, Shoulder and Hand) (82\%) and QuickDASH (79\%) 
questionnaires, although in these cases, meaningful change was measured using a very different methodology (Franchignoni et al. 2014). The low diagnostic specificity observed (2.6\%) is much lower than the rate reported for DASH (overall specificity, 74\%) (Franchignoni et al. 2014), although to our knowledge, the diagnostic accuracy of DASH has not yet been analyzed in the specific setting of DC, but rather in studies analyzing different diseases (Gummesson et al. 2006) or responsiveness to changes after corrective surgery for DC (Rodrigues et al. 2017). Its diagnostic specificity for DC thus is unknown and is probably much lower than rates reported for general upper arm disabilities. Notwithstanding, the URAM scale has been reported to outperform other scales in terms of its specificity for DC (Knobloch et al. 2012). Although we do not have data to confirm this superior performance, we did find a relatively good balance between sensitivity and specificity (around 60\%) in the underlying ROC curve (Fig. 2), suggesting good disease-specific performance in DC.

The theoretical advantage that the URAM scale offers over other scales is that it was designed to measure functional outcomes in DC, although its usefulness for assessing overall treatment outcomes has been questioned as it does not address aspects such as pain or cosmetic problems (Rodrigues et al. 2017).

The interpretability of the URAM scale can be assessed on the basis of clinical relevance and the minimal clinically important difference (MCID), which are measures of variations in scores over time that are perceived as important by patients or that reveal significant differences between patients. The clinical relevance of URAM score changes was demonstrated in the original study describing the development and validation of this tool through the observation of a significant correlation between variations in URAM and Tubiana scores after treatment (Beaudreuil et al. 2011). MCID refers to the smallest change in status that patients consider important. Estimated MCID values for the URAM scale in the literature are 2.9 points for patients treated with NA (Beaudreuil et al. 2011) and 10.5 points for those treated with open surgery (FSC or dermofasciectomy) (Rodrigues et al. 2017). The results of our meta-regression analysis are consistent with these results, as we detected an improvement of 1.67 points in the URAM scale for each change in Tubiana stage (improvement of approximately $45^{\circ}$ ). We are unable to compare our results with those for other scales such as DASH and QuickDASH, both validated for measuring outcomes in DC (Rodrigues et al. 2017), as none of the studies analyzed detected MCIDs that reached the "official" clinically important change (The DASH outcome measure 2019) or other independently established thresholds (Franchignoni et al. 2014). As indicated by a growing number of authors, thus, DASH, which is the most widely used tool for measuring treatment outcomes in DC, may not be the most useful tool for this purpose (Rodrigues et al. 2017).

The low specificity observed for the URAM scale in our meta-analysis has several explanations. On the one hand, our model was based on a series of assumptions, including the absence of false positives (perfect specificity) and the thresholds used to define DC. There is currently no agreement on where the line between disease and recurrence lies, although some progress is being made (Harrison et al. 2017). On the other hand, the URAM scale was specifically designed for DC, but it could theoretically be used in other diseases such as carpal tunnel syndrome, as it addresses hand mobility problems that are not specific to DC. Question 9, for example, evaluates problems with pinch, which is generally a greater problem in patients with carpal tunnel syndrome than in those with DC, who face more difficulties straightening their fingers. Additional sources of heterogeneity in our model are the diverse criteria used to measure contracture (Pratt et al. 2016), the different time points at which treatment outcomes were measured, and even doubts about the applicability of the scale in different languages and cultures, although high consistency has been reported for the validated versions of the URAM scale in several languages.

The limitations of this study are linked to the varying degrees of contracture severity in the samples analyzed, potential selection bias, and potential information bias as the URAM scale was not designed as a diagnostic test.

\section{Conclusions}

This meta-analysis shows that the URAM scale has high sensitivity and low specificity for DC, although it was sensitive to clinically significant changes following treatment.

\section{Abbreviations}

$\mathrm{DC}$

Ducpuytren's Contracture

URAM

Unité Rhumatologique des Affections de la Main

$\mathrm{CCH}$

Collagenase Clostridium Histolyticum

NA

Needle Aponeurotomy

FSC

Fasciectomy

STROBE

STrengthening the Reporting of OBservational studies in Epidemiology

HSROC

Hierarchical Summary Receiver Operating Characteristic 
ROC

Receiver Operating Characteristic

DASH

Disabilities of the Arm, Shoulder and Hand

QuickDASH

Short form of the DASH Questionnaire

MCID

Minimal Clinically Important Difference

\section{Declarations}

\section{Competing interests}

Not applicable

\section{Funding}

Not applicable

\section{Authors' contributions}

Conception and design: PVF, DGH, FJCH. Collection and assembly of data: DGH, PVF. Analysis: PVF. Interpretation of the data: PVF, DGH, FJCH, RSC, JEPJ, EGJ. Drafting of the manuscript: DGH, PVF. Critical revision and final approval of the article: PVF, DGH, FJCH, RSC, JEPJ, EGJ.

\section{Acknowledgements}

This article is part of the Doctoral Thesis of Diego Gómez-Herrero within the Doctoral Programme in Pharmacy at Granada University in Spain.

\section{Availability of supporting data}

Data relative to this work is available under request to the correspondence author.

\section{Ethical Approval and Consent to participate}

Not applicable

\section{Consent for publication}

All we (the authors) understand that the information will be published without we/we child or ward's/our relative's (circle as appropriate) name attached, but that full anonymity cannot be guaranteed. We understand that the text and any pictures or videos published in the article will be freely available on the internet and may be seen by the general public. The pictures, videosand text may also appear on other websites or in print, may be translated into other languages or used for commercial purposes. We have been offered the opportunity to read the manuscript.

\section{References}

1. Ball C, Pratt AL, Nanchahal J. Optimal functional outcome measures for assessing treatment for Dupuytren's disease: a systematic review and recommendations for future practice. BMC Musculoskelet Disord. 2013;14:131.

2. Beaudreuil J, Allard A, Zerkak D, Gerber RA, Cappelleri JC, Quintero N, Lasbleiz S, Bernabé B, Orcel P, Bardin T, URAM Study Group. Unité Rhumatologique des Affections de la Main (URAM) scale: development and validation of a tool to assess Dupuytren's disease-specific disability. Arthritis Care Res (Hoboken). 2011;63:1448-55.

3. Beaudreuil J, Ferrari M, Lellouche H, Roulot E, Yelnik A, Bardin T, Orcel P, Richette P. Iterative percutaneous needle aponeurotomy for Dupuytren's disease: Functional results at 5-year follow-up. Ann Phys Rehabil Med. 2018;61:e19.

4. Begg CB, Mazumdar M. Operating characteristics of a rank correlation test for publication bias. Biometrics. 1994;50:1088-101.

5. Bernabé B, Lasbleiz S, Gerber RA, Cappelleri JC, Yelnik A, Orcel P, Bardin T, Beaudreuil J. URAM scale for functional assessment in Dupuytren's disease: a comparative study of its properties. Joint Bone Spine. 2014;81:441-4. 
6. Binhammer P. Comparative Outcomes of Dupuytren Disease Treatment. Hand Clin. 2018;34:377-86.

7. Broekstra D. Epidemiology of Dupuytren disease unraveled: Prevalence, risk factors and disease course [dissertation]. Groningen (NL): Rijksuniversiteit Groningen; 2017. 196 p.

8. Eaton C. Evidence-based medicine: Dupuytren contracture. Plast Reconstr Surg. 2014;133:1241-51.

9. Eaton C. Dupuytren disease. In: Wolfe S, Hotchkiss R, Pederson W, Kozin S, Cohen M, editors. Green's operative hand surgery. 7th ed. Philadelphia (USA): Elsevier; 2017. pp. 155-78.

10. Engstrand C, Krevers B, Nylander G, Kvist J. Hand function and quality of life before and after fasciectomy for Dupuytren contracture. J Hand Surg Am. 2014;39:1333-43.

11. Engstrand C, Kvist J, Krevers B. Patients' perspective on surgical intervention for Dupuytren's disease - experiences, expectations and appraisal of results. Disabil Rehabil. 2016;38:2538-49.

12. Franchignoni F, Vercelli S, Giordano A, Sartorio F, Bravini E, Ferriero G. Minimal clinically important difference of the disabilities of the arm, shoulder and hand outcome measure (DASH) and its shortened version (QuickDASH). J Orthop Sports Phys Ther. 2014;44:30-9.

13. Gummesson C, Ward MM, Atroshi I. The shortened disabilities of the arm, shoulder and hand questionnaire (Quick DASH): validity and reliability based on responses within the full-length DASH. BMC musculoskelet Disord. 2006;7:44.

14. Harrison E, Tan W, Mills N, Karantana A, Sprange K, Duley L, Elliott D, Blazeby J, Hollingworth W, Montgomery AA, Davis T. A feasibility study investigating the acceptability and design of a multicentre randomised controlled trial of needle fasciotomy versus limited fasciectomy for the treatment of Dupuytren's contractures of the fingers (HAND-1): study protocol for a randomized controlled trial. Trials. 2017;18:392.

15. Higgins JPT, Green S, eds. Cochrane Handbook for Systematic Reviews of Interventions Version 5.1.0. The Cochrane Collaboration, 2011. Available at: https://www.cochrane-handbook.org. Accessed July 27, 2019.

16. Higgins JPT, Thompson SG. Quantifying heterogeneity in a meta-analysis. Stat Med. 2002;21:1539-58.

17. Institute of Medicine (US) Committee on Standards for Systematic Reviews of Comparative Effectiveness Research; Eden J, Levit L, Berg A, Morton S, eds. Finding What Works in Health Care: Standards for Systematic Reviews. Washington (DC): National Academies Press (US); 2011. Available at: https://www.ncbi.nlm.nih.gov/books/NBK209518/pdf/Bookshelf_NBK209518.pdf. Accessed July 27, 2019.

18. Knobloch K, Kuhn M, Sorg H, Vogt PM. German version of the Unite Rhumatologique des Affections de la Main (URAM) scale in Dupuytren's disease: the need for a uniform definition of recurrence. Comment on the article by Beaudreuil et al. Arthritis Care Res (Hoboken). 2012; 64:793; author reply 794.

19. Pratt AL, Ball C. What are we measuring? A critique of range of motion methods currently in use for Dupuytren's disease and recommendations for practice. BMC Musculoskelet Disord. 2016;17:20.

20. Reitsma JB, Glas AS, Rutjes AW, Scholten RJ, Bossuyt PM, Zwinderman AH. Bivariate analysis of sensitivity and specificity produces informative summary measures in diagnostic reviews. J Clin Epidemiol. 2005;58:982-90.

21. Rodrigues JN, Zhang W, Scammell BE, Davidson D, Fullilove S, Chakrabarti I, Russell PG, Davis TR. Recovery, responsiveness and interpretability of patient-reported outcome measures after surgery for Dupuytren's disease. J Hand Surg Eur Vol. 2017;42:301-9.

22. Rutter CM, Gatsonis CA. A hierarchical regression approach to meta-analysis of diagnostic test accuracy evaluations. Stat Med. 2001;20:2865-84.

23. Scherman P, Jenmalm P, Dahlin LB. One-year results of needle fasciotomy and collagenase injection in treatment of Dupuytren's contracture: A twocentre prospective randomized clinical trial. J Hand Surg Eur Vol. 2016;41:577-82.

24. Stromberg J, Ibsen-Sorensen A, Friden J. Comparison of Treatment Outcome After Collagenase and Needle Fasciotomy for Dupuytren Contracture: A Randomized, Single-Blinded, Clinical Trial With a 1-Year Follow-Up. J Hand Surg Am. 2016;41:873-80.

25. Stromberg J, Ibsen-Sorensen A, Friden J. Percutaneous Needle Fasciotomy Versus Collagenase Treatment for Dupuytren Contracture: A Randomized Controlled Trial with a Two-Year Follow-up. J Bone Joint Surg Am. 2018;100:1079-86.

26. The DASH outcome measure. Available at: http://www.dash.iwh.on.ca/. Accessed July 27, 2019.

27. Verstreken F, Degreef I, Decramer A, Libberecht K, Vanhove W, Datco A, Vanhaecke J, Clermont D, Duerinckx J. Effectiveness and safety of collagenase Clostridium histolyticum in Dupuytren's disease: an observational study in Belgium. Acta Orthop Belg. 2016;82:397-404.

28. von Elm E, Altman DG, Egger M, Pocock SJ, Gotzsche PC, Vandenbroucke JP. The Strengthening the Reporting of Observational Studies in Epidemiology (STROBE) Statement: guidelines for reporting observational studies. Int J Surg. 2014;12:1495-9.

29. Warwick D, Arner M, Pajardi G, Reichert B, Szabo Z, Masmejean EH, Fores J, Chapman DS, Gerber RA, Huard F, Seghouani A, Szczypa PP. POINT X Investigators. Collagenase clostridium histolyticum in patients with Dupuytren's contracture: results from POINT X, an open-label study of clinical and patient-reported outcomes. J Hand Surg Eur Vol. 2015;40:124-32.

30. Warwick D. Dupuytren's disease: my personal view. J Hand Surg Eur Vol. 2017;42:665-72.

31. Wiseman J, Tree K, Guio-Aguilar P, Pratt G, Nizzaro D, Leung M, Leong J. Collagenase Management of Multicord Dupuytren's Disease under Intravenous Sedation: A Prospective Cohort Study. Plast Reconstr Surg Glob Open. 2019;7:e2133.

\section{Figures}




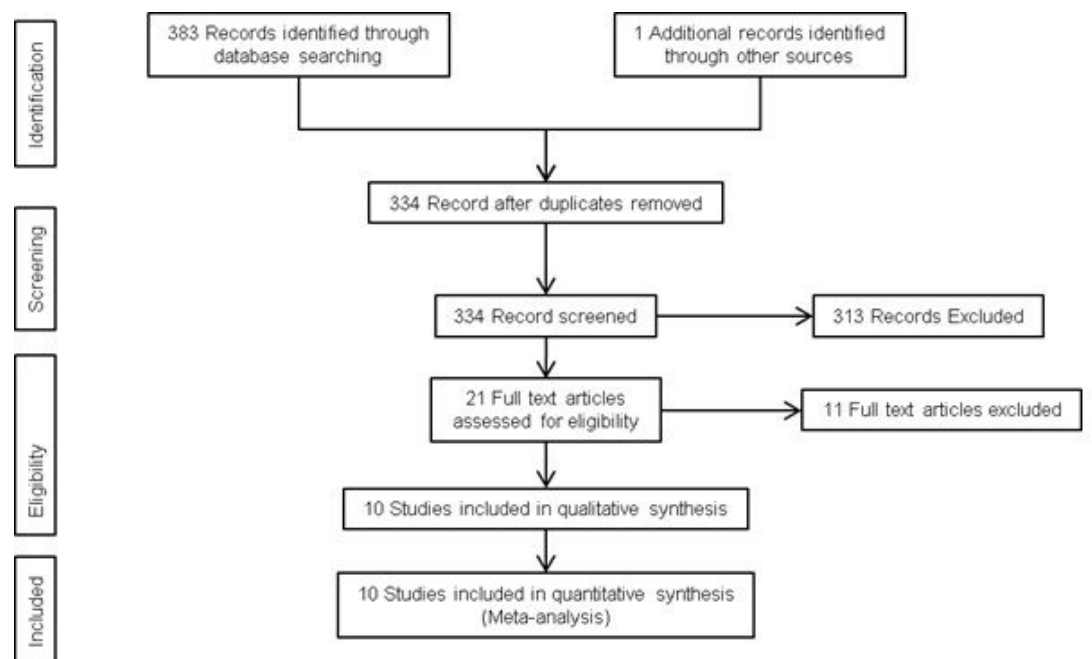

383 records identified through database searches

1 additional record identified through other sources

334 records after removal of duplicates

334 records screened

313 records excluded

21 full-text articles assessed for eligibility

11 full-text articles ex cluded

10 studies included in quali tative synthesis

10 studies included in quantitative synthesis (meta-analysis)

\section{Figure 1}

Flowchart of study inclusion

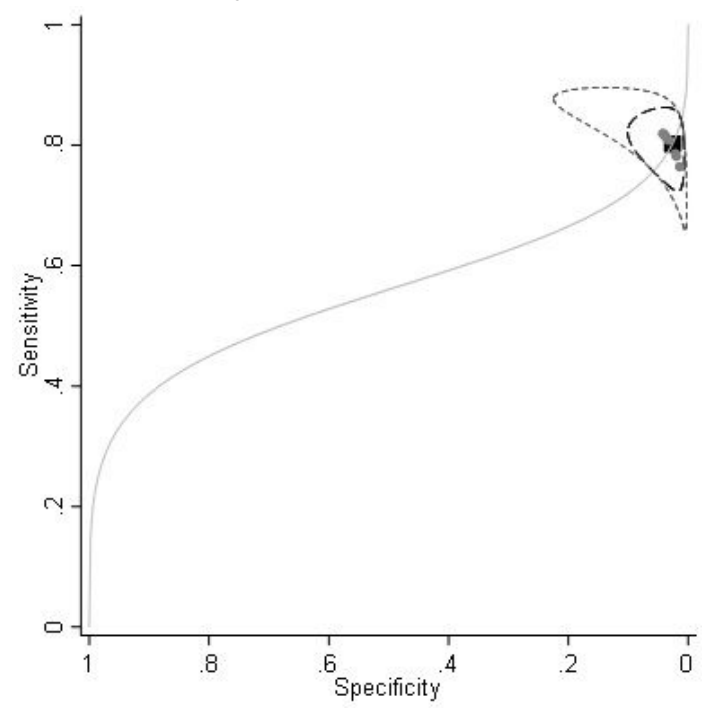

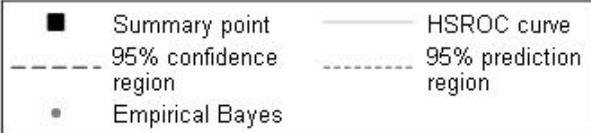

\section{Figure 2}

HSCROC curve with 95\% confidence region and empirical Bayes estimate and $95 \%$ prediction region 


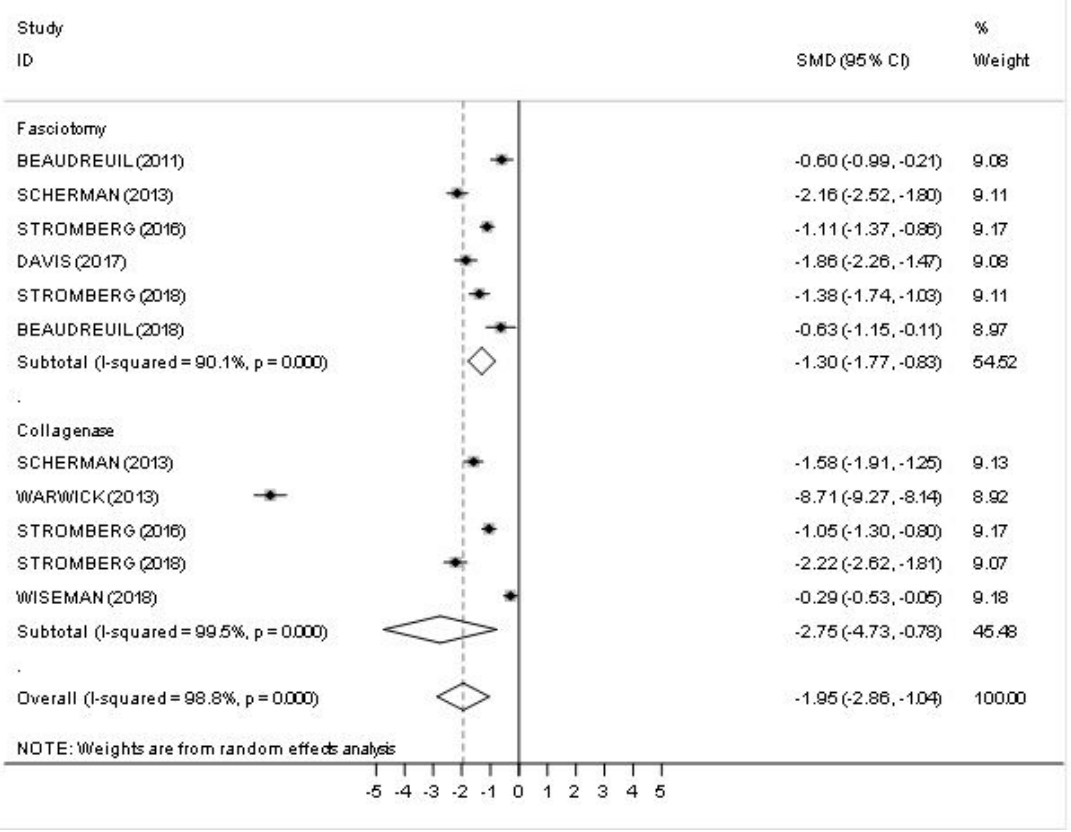

\section{Figure 3}

Meta-analysis of differences in URAM scores according to procedure

\section{Supplementary Files}

This is a list of supplementary files associated with this preprint. Click to download.

- PlainEnglishSummary.docx

- PRISMA2009checklist.doc 